\title{
Effects of Thin-Film Spin-On Glass Dielectric Loss on the Performance of the Uniformly Distributed $R C$ Notch Network
}

\author{
Edward S. Kolesar, Jr., Senior Member, IEEE
}

\begin{abstract}
The influence of dielectric loss on the performance of the thin-film uniformly distributed $R C$ notch network is considered on a theoretical and experimental basis. Dielectric loss is shown to have a significant effect on the network's notch tuning frequency and the magnitude of the notch tuning resistance. An open-circuit voltage transfer function which includes a frequency-dependent dielectric loss parameter is analyzed. Double precision computed results for the first-order and higher order notch tuning frequency and notch resistance values as a function of the dielectric loss parameter are presented. The application of a proposed dielectric loss compensation technique significantly reconciles the differences between the theoretical and experimental results measured from $R C$ notch networks fabricated with a VLSI interlevel silicon dioxide spin-on glass planarizing dielectric.
\end{abstract}

\section{INTRODUCTION}

M ODERN microelectronic integrated circuit (IC) design continues to have a recurring requirement to realize the property of inductance. Although flat spiral inductors with micrometer-scaled dimensions and values of a few microhenries can be realized with conventional thin-film IC processing techniques, the inherent resistance of the semiconductor substrate often reduces the quality factor $(Q)$ to a value less than unity. Alternatively, relatively complex discrete IC component designs have been utilized to simulate inductors. However, the interdependence of the actual values of the circuit parameters frequently manifest their sensitivity when reproducible performance standards are enforced in large-scale production applications [1]-[3]. Fortunately, the desirable frequency selective properties of conventionally tuned LC circuits can be realized with distributed $R C$ notch networks that are readily fabricated with standard IC processing techniques [4], [5].

Over the past $30 \mathrm{a}$, the electrical performance of thin-film distributed $R C$ notch networks have been thoroughly analyzed by many investigators [4]-[89]. A significant number of these investigators have studied the influence of geometrical tapering on the performance of the distributed $R C$ struc-

Manuscript received July 13, 1990; revised November 20, 1990. This work was supported by the United States Air Force, Air Force Systems Command, Human Systems Division, U.S.A.F. School of Aerospace Medicine, and the Crew Technology Branch, Brooks AFB, San Antonio, TX, under Contract F33615-K-0610.

The author is with the Department of Electrical and Computer Engineering, Air Force Institute of Technology, Wright-Patterson AFB, Dayton, $\mathrm{OH}$ 45433-6583.

IEEE Log Number 9143175. ture [9], [10], [16], [20], [22], [24]-[26], [29], [32], [36], [39]-[42], [51], [57], [58], [62], [64], [77], [79], [80], [82], [86]. Additionally, voltage tunable distributed $R C$ notch networks have been realized with thick-film, thin-film, and monolithic silicon IC processes [7]-[9], [19], [23], [30], [31], [54]-[56], [63], [66], [69], [72], [74], [80], [83], [85]. Nevertheless, because of the difficulties associated with precisely controlling the fabrication process, the tolerance values of the distributed $R$ - and $C$-parameters are often unacceptable. Numerous parameters affecting the distributed $R C$ notch network have been carefully dealt with in many experimental studies. The experimental results frequently manifest significant disagreement with the fundamental (ideal) theory developed by Kaufman [7]. The cause of these differences have been attributed to many sources, which include, load impedances [18]-[21], [29], [63], [76]; parasitic inductance [48], [63]; distributed shunt resistance [60], [69]; and dielectric loss [33], [40], [44], [60], [63], [84], [86]-[89].

In this paper, the electrical performance of uniformly distributed $R C$ notch networks fabricated using conventional IC thin-film vacuum deposition techniques and a VLSI interlevel silicon dioxide spin-on glass (SOG) dielectric planarization material [90] is reported. Similar to the precise computations of the ideal notch tuning parameters reported by Huelsman [37], a complementary set of normalized first-order (dominant) and higher order (nondominant) tuning parameters for a uniformly distributed $R C$ notch network with dielectric loss is reported. The proposed dielectric loss compensation technique significantly reduces the discrepancy between the experimental results and those predicted by the ideal (lossless) theory [7], [37]. These results should be of interest to those who are interested in applying this useful circuit.

\section{UNiformly Distributed $R C$ Notch Network THEORY}

The well-known ideal uniformly distributed $R C$ notch network structure and circuit symbol are shown in Fig. 1. Fig. 2 depicts a convenient equivalent circuit model of the distributed $R C$ structure that includes dielectric loss via the inclusion of an incremental conductance parameter $\left[g_{S}(\omega)\right.$. $\Delta x]$ which is in series with the incremental capacitance [33], [40], [44], [60], [83]. Carson et al. report on an open-circuit voltage transfer function $[T(\omega)]$ for the uniformly distributed $R C$ notch network which incorporates the effect of dielectric 


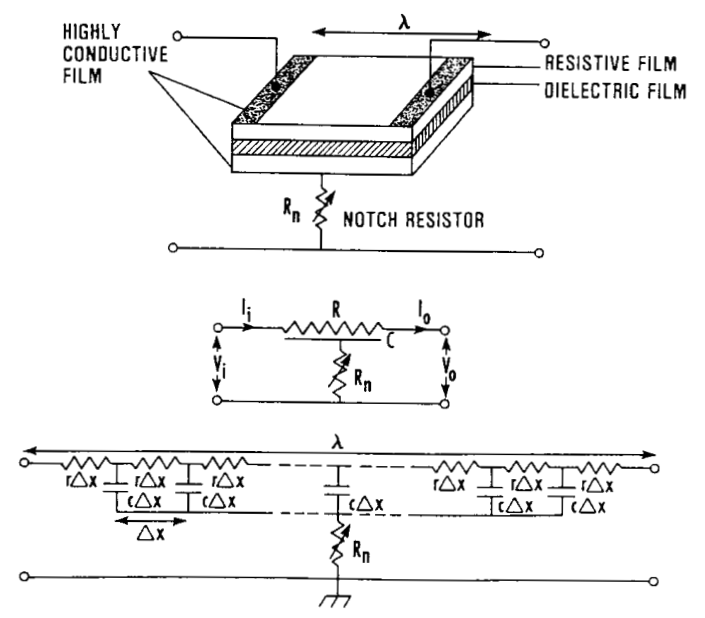

Fig. 1. Uniformly distributed $R C$ notch network structure and circuit symbol.

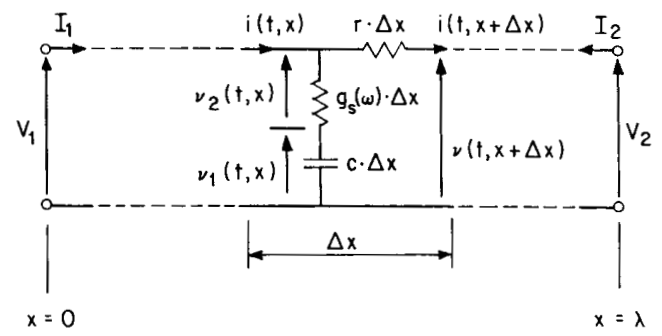

Fig. 2. Incremental equivalent circuit model of the uniformly distributed $R C$ structure with dielectric loss.

loss as:

$$
T(\omega)=\frac{V_{o}(\omega)}{V_{i}(\omega)}=\frac{\alpha+\xi \sinh (\xi)}{\alpha \cosh (\xi)+\xi \sinh (\xi)}
$$

where

$$
\begin{array}{ll}
\xi & {\left[\frac{s r c \lambda^{2}}{1+s c / g_{s}(s)}\right]^{1 / 2}=\left[\frac{s R C}{1+s R C \eta(s)}\right]^{1 / 2}} \\
& =\left[\frac{j \delta}{1+j \delta \eta(\omega)}\right]^{1 / 2}, \\
\delta & \omega R C=2 \gamma^{2}(\text { normalized notch frequency param- } \\
& \text { eter), } \\
\gamma & \left(\omega / \omega_{0}\right)^{1 / 2}, \\
\eta(\omega) & {\left[R G_{s}(\omega)\right]^{-1}=\left[R_{s}(\omega) / R\right] \text { (dielectric loss param- }} \\
& \text { etr), } \\
G_{s}(\omega) & \int_{0}^{\lambda} g_{s}(\omega) \cdot d x=\lambda g_{s}(\omega), \\
R & r_{s}(\omega) / \lambda, \\
R & r \lambda(\text { distributed resistance), } \\
C & c \lambda(\text { distributed capacitance), } \\
\alpha & R / R_{n} \text { (notch resistance ratio parameter), } \\
\omega_{0} & 2 / R C \text { (characteristic frequency parameter), } \\
\lambda & \text { net length of the distributed } R C \text { structure } \\
s & \text { Laplace transform variable. }
\end{array}
$$

In order for the transfer function to have a zero of transmission, the numerator of $T(\omega)$ must be zero. That is:

$$
\alpha+\xi \sinh (\xi)=0 .
$$

This complex variable expression can be separated into two real-variable equations:

$$
\alpha(\delta) \cdot \tan [b(\delta)]=-b(\delta) \tanh [\alpha(\delta)]
$$

and

$$
\begin{aligned}
\alpha=-\{a(\delta) \cdot \sinh [a(\delta)] \cdot \cos [b(\delta)] \\
-b(\delta) \cdot \cosh [a(\delta)] \cdot \sin [b(\delta)]\}
\end{aligned}
$$

where

$$
\begin{aligned}
a(\delta)= & \left\{\frac{1}{2}\left[\frac{\delta}{\delta^{2} \eta^{2}(\omega)+1}\right]\right. \\
& \left.\cdot\left[\delta \eta(\omega)+\left\{\delta^{2} \eta^{2}(\omega)+1\right\}^{1 / 2}\right]\right\}^{1 / 2} \\
b(\delta)= & \frac{\delta}{2\left[\delta^{2} \eta^{2}(\omega)+1\right]} \\
& \cdot\left\{\frac{1}{2}\left[\frac{\delta}{\delta^{2} \eta^{2}(\omega)+1}\right]\left[\delta \eta(\omega)+\left\{\delta^{2} \eta^{2}(\omega)+1\right\}^{1 / 2}\right]\right\}
\end{aligned}
$$

Equation (3) is a transcendental expression that is exclusively a function of the normalized notch frequency and dielectric loss parameters, and it has a solution set with an infinite number of elements, denoted by $\left\{\delta_{n}\right\}$. The physically practical solution set corresponds to values for $n$-odd ( $\alpha$ is negative for $n$-even). On the other hand, (4) is a function of the notch resistance ratio, the normalized frequency, and the dielectric loss parameters. Therefore, by considering discrete values of $\eta(\omega)$, (3) can be used to calculate solutions for the normalized notch frequency parameter that yields a null. In turn, (4) yields a corresponding value of the notch resistance ratio parameter.

Solutions of (2) have been reported by several authors [33], [40], [44], [60], [63], [84]. However, there are significant discrepancies in the published results, and the differences increase in magnitude with increasing values of $n$ (higher order (nondominant) solutions). Huelsman has addressed this issue for the ideal (lossless dielectric) case, and he has published an accurate set of results for $n=1,3$, and 5 [37]. Depending upon the particular application, choice of materials, and geometry of the uniformly distributed $R C$ notch network, the higher order solutions might be advantageous.

The solutions of interest for the uniformly distributed $R C$ notch network with dielectric loss were found using (3) and (4) along with the algorithm developed by Shampine and Allen [91] for calculating the roots of nonlinear equations. The computations were accomplished using a DEC VAX $11 / 780$ computer and extended double precision arithmetic (33 significant digits). In those cases where a physically realistic solution exists, the results are summarized in Table I for the first-order and higher order notch tuning parameters 
TABLE I

Tuning Parameters for a Uniformly Distributed $R C$ Notch Network with Dielectric Loss

\begin{tabular}{|c|c|c|c|}
\hline $\begin{array}{c}\text { Dielectric Loss } \\
\text { Parameter } \\
{\left[\eta(\omega)=R_{s}(\omega) / R\right]}\end{array}$ & $\begin{array}{l}\text { Solution } \\
\text { Iterate } \\
{[n]}\end{array}$ & $\begin{array}{c}\text { Normalized Notch } \\
\text { Frequency Parameter } \\
{\left[2\left(\omega / \omega_{0}\right]\right.}\end{array}$ & $\begin{array}{c}\text { Notch Resistance } \\
\text { Ratio Parameter } \\
{\left[\alpha=R / R_{n}\right]}\end{array}$ \\
\hline \multirow[t]{6}{*}{$1 \times 10^{-6}$} & 1 & $1.118681613922 \times 10^{1}$ & $1.779924056969 \times 10^{1}$ \\
\hline & 3 & $1.493026458740 \times 10^{2}$ & $3.456459447459 \times 10^{4}$ \\
\hline & 5 & $4.455778625488 \times 10^{2}$ & $3.215179314740 \times 10^{7}$ \\
\hline & 7 & $9.002168823242 \times 10^{2}$ & $2.478421210191 \times 10^{10}$ \\
\hline & 9 & $1.513659423828 \times 10^{3}$ & $1.760722242884 \times 10^{13}$ \\
\hline & 11 & $2.286501220703 \times 10^{3}$ & $1.201363757055 \times 10^{16}$ \\
\hline \multirow[t]{6}{*}{$1 \times 10^{-5}$} & 1 & $1.118837253571 \times 10^{1}$ & $1.780551392522 \times 10^{1}$ \\
\hline & 3 & $1.495273742676 \times 10^{2}$ & $3.501910341207 \times 10^{4}$ \\
\hline & 5 & $4.475065673828 \times 10^{2}$ & $3.429244440421 \times 10^{7}$ \\
\hline & 7 & $9.080351928711 \times 10^{2}$ & $2.975429493178 \times 10^{10}$ \\
\hline & 9 & $1.535892944336 \times 10^{3}$ & $2.621635011890 \times 10^{13}$ \\
\hline & 11 & $2.337960693359 \times 10^{3}$ & $3.905103452445 \times 10^{16}$ \\
\hline \multirow[t]{6}{*}{$1 \times 10^{-4}$} & 1 & $1.120397872925 \times 10^{1}$ & $1.786848895872 \times 10^{1}$ \\
\hline & 3 & $1.518634887695 \times 10^{2}$ & $4.003748670351 \times 10^{4}$ \\
\hline & 5 & $4.692538452148 \times 10^{2}$ & $6.872888059894 \times 10^{7}$ \\
\hline & 7 & $1.009660461426 \times 10^{3}$ & $2.572398770692 \times 10^{11}$ \\
\hline & 9 & $1.905846313477 \times 10^{3}$ & $6.501208415976 \times 10^{15}$ \\
\hline & 11 & $3.868025634766 \times 10^{3}$ & $9.857981633528 \times 10^{22}$ \\
\hline \multirow[t]{3}{*}{$5 \times 10^{-4}$} & 1 & $1.127443218231 \times 10^{1}$ & $1.815419705588 \times 10^{1}$ \\
\hline & 3 & $1.647343902588 \times 10^{2}$ & $7.939431449244 \times 10^{4}$ \\
\hline & 5 & $7.520238647461 \times 10^{2}$ & $3.946154637978 \times 10^{10}$ \\
\hline \multirow[t]{2}{*}{$1 \times 10^{-3}$} & 1 & $1.136511001587 \times 10^{1}$ & $1.852532038113 \times 10^{1}$ \\
\hline & 3 & $1.912521087646 \times 10^{2}$ & $2.649243928920 \times 10^{5}$ \\
\hline $5 \times 10^{-3}$ & 1 & $1.221794319153 \times 10^{1}$ & $2.220782218770 \times 10^{1}$ \\
\hline $1 \times 10^{-2}$ & 1 & $1.379062393188 \times 10^{1}$ & $2.996292709715 \times 10^{1}$ \\
\hline $1.5 \times 10^{-2}$ & 1 & $1.680923652649 \times 10^{1}$ & $4.874677780074 \times 10^{1}$ \\
\hline $1.845 \times 10^{-2}$ & 1 & $2.707184005905 \times 10^{1}$ & $1.617500213638 \times 10^{2}$ \\
\hline
\end{tabular}

corresponding to discrete values of the dielectric loss parameter. It is noted that several authors, [33], [40], [44], have published a limited precision, small subset of the calculated results presented in Table I for the first-order $(n=1)$ solution iterate; the deviations are typically on the order of $\pm 0.4 \%$.

\section{Experimental Design}

In order to determine the dielectric loss characteristics of the amorphous silicon dioxide SOG thin films as a function of frequency for a specific uniformly distributed $R C$ notch network design, an auxiliary parallel plate capacitor with the same critical dimensions as the notch network was fabricated in situ. Although the dielectric thin film of the in situ test capacitor is not exactly the same as that in the adjacent distributed $R C$ notch network, it is assumed in the proposed compensation technique that it yields a reasonably accurate estimate of the film's dielectric loss. Table II summarizes the critical dimensions and the ideal notch tuning parameters associated with two distinct uniformly distributed $R C$ notch network designs.

The performance of the uniformly-distributed $R C$ notch networks was measured using a swept-frequency function generator (Hewlett-Packard, model HP 3314A, Palo Alto, CA) and a high input impedance (10 $\mathrm{M} \Omega$ and $9 \mathrm{pF})$ digital display gain/phase detector (Hewlett-Packard, model HP $3575 \mathrm{~A}$ ) configured to directly measure the notch network's open-circuit voltage transfer function $\left[20 \log _{10}\left(V_{o} / V_{i}\right)\right]$. In order to achieve a prominent notch depth (typically greater than $-60 \mathrm{~dB})$, the value of the lumped notch tuning resistance parameter $(\alpha)$ is established via $R_{n}$ with a precision
TABLE II

Critical Parameters of the Uniformly Distributed $R C$ NOTCH NETWORKS

\begin{tabular}{lcc}
\hline Parameter & $\begin{array}{c}\text { Device } \\
\text { Structure 1 }\end{array}$ & $\begin{array}{c}\text { Device } \\
\text { Structure 2 }\end{array}$ \\
\hline $\begin{array}{l}\text { Distributed Resistance }(R) \\
\text { Film Thickness }(\AA)\end{array}$ & 71 & 126 \\
$\begin{array}{l}\text { Measured Distributed } \\
\text { Resistance }(R=r \lambda)(\Omega)\end{array}$ & $1.16 \times 10^{8}$ & $8.51 \times 10^{8}$ \\
$\begin{array}{l}\text { Distributed Capacitance }(C) \\
\text { SOG Film Thickness }(\AA)\end{array}$ & 1285 & 4783 \\
$\begin{array}{l}\text { Calculated Distributed } \\
\text { Capacitance }(C=c \lambda)(\mathrm{F})\end{array}$ & $4.9 \times 10^{-11}$ & $7.36 \times 10^{-10}$ \\
$\begin{array}{l}\text { Resistive Film's } \\
\text { Electrode Gap } \\
(\lambda \text {-parameter in Fig. 1) }\end{array}$ & & \\
$\begin{array}{l}\text { Surface Area of the } \\
\text { Distributed } R C \\
\text { Structure }\left(\mathrm{cm}^{2}\right) \\
\text { Calculated Characteristic } \\
\text { Frequency Parameter } \\
\left(\omega_{0}=2 / R C\right) \text { (rad) }\end{array}$ & 203 & 508 \\
\hline
\end{tabular}

resistance (0.01- $\Omega$ resolution) decade box (Electro-Scientific Industries, Inc., model DB52, Portland, OR). An earlier publication by the author [87] describes the instrumentation arrangement used to characterize the uniformly distributed $R C$ notch network's performance.

The relative errors (expressed as a percent) between the measured and theoretical ideal notch network tuning parameters [37] were calculated using:

$$
\frac{\text { Parameter }_{\text {measured }}-\text { Parameter }_{\text {theoretical }}}{\text { Parameter }_{\text {theoretical }}} \times 100=\Delta \text { Parameter } .
$$




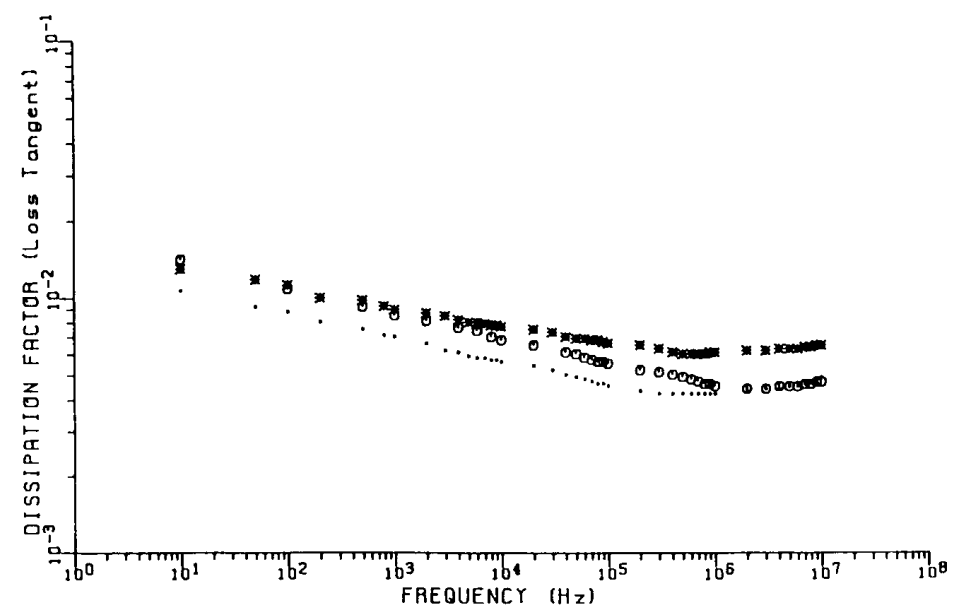

Fig. 3. Dissipation factor (loss tangent) versus frequency for the in situ test capacitor structures. Key: $O$ : arbitrary reference capacitor $(1213-\AA$ thick dielectric film), *: test capacitor for the $508-\mu \mathrm{m}$ wide electrode gap structure; $\bullet$ : test capacitor for the $203-\mu \mathrm{m}$ wide electrode gap structure.

An impedance analyzer (Hewlett-Packard, model 4192A) was used to accomplish the dielectric loss measurements. The equivalent circuit model selected for these measurements was consistent with that of the notch network (Fig. 2). That is, the test capacitor's dielectric loss model consists of a frequency-dependent resistance $\left[R_{S}(\omega)\right]$ in series with a capacitance $\left(C_{S}\right)$. The dielectric's dissipation factor $(D)$ (loss tangent) is given by

$$
D=\omega \cdot R_{s}(\omega) \cdot C_{s} .
$$

To determine the influence of the dielectric loss, (6) was used to generate a plot of the $R_{S}(\omega)$-parameter versus frequency. A specific value of $R_{S}(\omega)$ corresponding to the ideal network's notch frequency was then identified. Accordingly, the ratio of $R_{S}(\omega)$ to $R$ yields a reasonable first-order estimate of the dielectric loss parameter $[\eta(\omega)]$. The dielectric loss compensation scheme was then implemented by linearly interpolating between the discrete values of $\eta(\omega)$ in Table I to determine revised estimates of the lossy-dielectric uniformly-distributed $R C$ notch network's tuning parameters. Finally, (5) was used to calculate the corresponding tuning parameter errors.

\section{Experimental Results and Discussion}

The uniformly distributed $R C$ notch networks were fabricated on glass microscope slide substrates. The highly conductive lower electrode (Fig. 1) was photolithographically patterned from an $8000-\AA$ thick sputtered aluminum film (resistance less than $0.2 \Omega$ for $f \leq 5000 \mathrm{~Hz}$ ). The silicon dioxide SOG dielectric thin film was applied and thermally cured consistent with the vendor's recommendations [90]. The distributed resistance film was realized by thermally evaporating a thin film of high-purity copper (99.99\%) through an etched metal mask; the corresponding low-resistivity contacts were also vacuum deposited as thicker copper films. The in situ parallel plate test capacitors were similarly
TABLE III

Tuning Parameter Errors for the Ideal (Lossless Dielectric) Uniformly Distributed $R C$ Notch Networks

\begin{tabular}{cc}
\hline Device Structure & $\begin{array}{c}\text { Tuning Parameter } \\
\text { Errors (percent) }\end{array}$ \\
\hline 203- $\mu$ m Wide Electrode Gap & \\
Notch Network $(n=3$ solution iterate) & 11.8 \\
$\Delta f_{n}$ & -8.53 \\
$\Delta R_{n}$ & 9.33 \\
$\Delta \alpha$ & \\
\hline 508- $\mu$ m Wide Electrode Gap & 7.18 \\
Notch Network $n=5$ solution iterate) & -14.73 \\
$\Delta f_{n}$ & 17.271 \\
$\Delta R_{n}$ & \\
$\Delta \alpha$ &
\end{tabular}

fabricated, except that the uppermost electrode was realized during the deposition of the $R C$ notch network's low-resistivity copper film contacts.

Table III summarizes the tuning parameter errors associated with the two uniformly distributed $R C$ notch network devices that were calculated with respect to the ideal (lossless dielectric) theoretical results. It is noted that the tuning parameter errors are quite substantial.

Fig. 3 depicts the dissipation factor measurements associated with the test capacitor structures. An arbitrary control test capacitor structure with a $1213-\AA$ thick dielectric film was included in the measurements. As expected for an amorphous dielectric thin film which contains a large number of defects, there is a corresponding broad distribution of relaxation time constants which manifest themselves via the relatively constant dissipation factor measurements. The limited portion of the dissipation factor data that appears to increase with increasing frequency can be attributed to the parasitic electrode contact impedance effects. That is, although the impedance analyzer compensates for stray and residual impedance effects associated with the leads and test fixture, it 


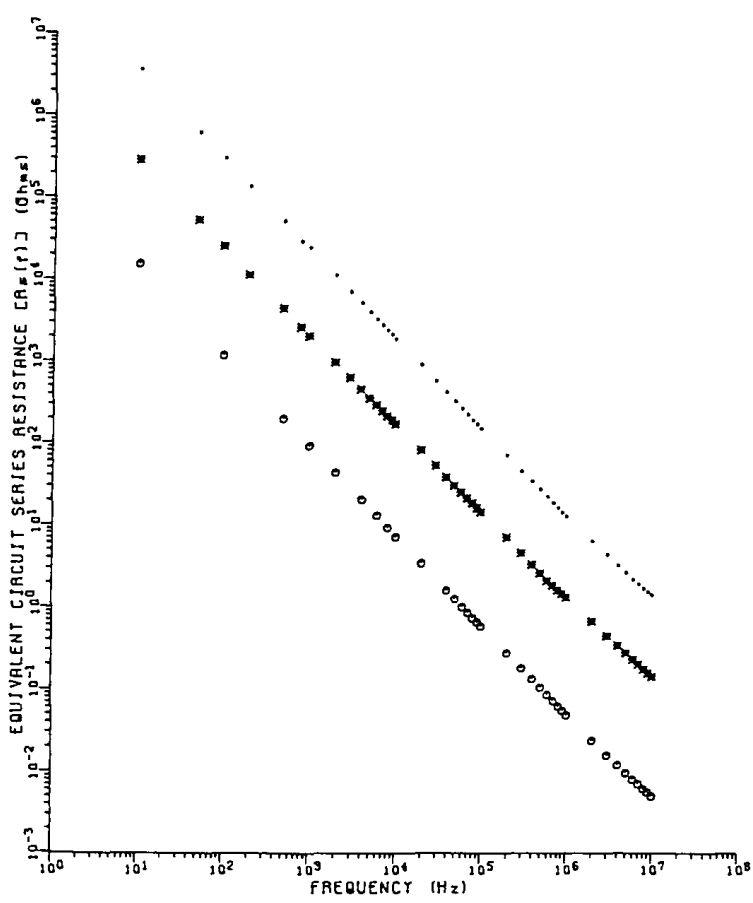

Fig. 4. Equivalent circuit series resistance $\left[R_{s}(f)\right]$ versus frequency for the in situ test capacitor structures. Key: $O$ : arbitrary reference capacitor (1213- $\AA$ thick dielectric film), *: test capacitor for the $508-\mu \mathrm{m}$ wide electrode gap structure; $\bullet$ : test capacitor for the $203-\mu \mathrm{m}$ wide electrode gap structure.

cannot do the same for the notch network's contact effects. Consequently (6) can be more accurately expressed as

$$
D=\omega \cdot R_{s}(\omega) \cdot C_{s}+\omega \cdot R_{s}^{\prime}(\omega) \cdot C_{s}
$$

where $R_{s}^{\prime}(\omega)$ is the parasitic contact resistance. This effect is only significant for large capacitance values or very high frequencies. For example, the $508-\mu \mathrm{m}$ wide electrode gap notch network has a measured capacitance of approximately $7.4 \times 10^{-10} \mathrm{~F}$ (Table II). If $f=6 \times 10^{6} \mathrm{~Hz}$ and $R_{s}^{\prime}(\omega)=1$ $\Omega$, then $\omega \cdot R_{s}^{\prime}(\omega) \cdot C_{S}=0.023$, which is of the same order of magnitude as $\omega \cdot R_{s}(\omega) \cdot C_{S}$. Fortunately, the practical upper notch frequency limit $\left(1 \times 10^{5} \mathrm{~Hz}\right)$ of the experimental distributed $R C$ notch networks is well below the threshold where contact effects become significant.

The test capacitor's corresponding equivalent series resistance $\left[R_{S}(f)\right]$ was calculated from the data in Fig. 3 and (6). The low-frequency $\left(f \leq 6 \times 10^{5} \mathrm{~Hz}\right)$ capacitance value of the two test structures was observed to be nearly constant. (The average capacitance values were $7.36 \times 10^{-10} \mathrm{~F}$ for the capacitor corresponding to the $508-\mu \mathrm{m}$ wide electrode gap $R C$ notch network device, and $4.9 \times 10^{-11} \mathrm{~F}$ for the 203- $\mu \mathrm{m}$ wide electrode gap structure). The plot of $R_{S}(f)$ versus frequency is depicted in Fig. 4.

After implementing the dielectric loss compensation scheme, the tuning parameter errors were calculated using (6). The results are summarized in Table IV.
TABLE IV

Dielectric Loss Compensated Tuning Parameter Errors FOR tHe UNIFORMLY Distributed $R C$ Notch Networks

\begin{tabular}{|c|c|c|}
\hline & $\begin{array}{c}203-\mu \mathrm{m} \text { Wide } \\
\text { Electrode Gap Structure } \\
(n=3 \text { solution iterate })\end{array}$ & $\begin{array}{c}508-\mu \mathrm{m} \text { Wide } \\
\text { Electrode Gap Structure } \\
(n=5 \text { solution iterate })\end{array}$ \\
\hline \multicolumn{3}{|c|}{ Dielectric Loss Compensated } \\
\hline \multicolumn{3}{|c|}{ Tuning Parameters } \\
\hline$R_{s}(f)(\Omega)$ & $3.548611 \times 10^{3}$ & $2.112423 \times 10^{4}$ \\
\hline$\eta(f)^{*}$ & $3.541528 \times 10^{-5}$ & $2.518988 \times 10^{-5}$ \\
\hline $2\left(\omega / \omega_{o}\right)^{* *}$ & $1.500172 \times 10^{2}$ & $4.509212 \times 10^{2}$ \\
\hline$f_{n}(\mathrm{~Hz})$ & $4.862923 \times 10^{3}$ & $1.161966 \times 10^{2}$ \\
\hline$R_{n}(\Omega)$ & $2.780553 \times 10^{3}$ & $2.170291 \times 10^{1}$ \\
\hline$\alpha$ & $3.603600 \times 10^{4}$ & $3.863999 \times 10^{7}$ \\
\hline \multicolumn{3}{|c|}{ Compensated Tuning } \\
\hline \multicolumn{3}{|c|}{ Parameter Errors (percent) } \\
\hline$\Delta f_{n}$ & 9.25 & 5.85 \\
\hline$\Delta R_{n}$ & -4.62 & 3.21 \\
\hline$\Delta \alpha$ & 4.85 & -3.11 \\
\hline \multicolumn{3}{|c|}{$\begin{array}{l}{ }^{*} \text { Calculated from }\left[R_{S}(f) / R\right] \\
{ }^{* *} \text { Linearly interpolated from Table I }\end{array}$} \\
\hline
\end{tabular}

Comparison of the uniformly distributed $R C$ notch network tuning parameter errors associated with the ideal (Table III) and dielectric loss compensated (Table IV) analyses suggests that the ideal (lossless dielectric) calculations are fundamentally useful for identifying approximate estimates of the notch tuning parameters $\left(f_{n}\right.$ and $\left.R_{n}\right)$. When the dielectric manifests a significant loss component in the vicinity of the intended notch frequency, the tuning parameter errors are quite large.

The potential sources that contribute to these errors are numerous, and include the effects of several idealized assumptions:

1) zero contact resistance;

2) zero stray and parasitic lead and test fixture impedances;

3) infinite instrumentation input impedance (for an exact open-circuit voltage measurement);

4) lossless dielectric,

5) homogeneous, defect-free thin films.

A complete identification and reconciliation of the performance effects caused by these sources is a nearly impossible task. However, dielectric losses appear to be a significant contributor to the errors involved; they are especially influential with respect to establishing the value of the lumped notch resistance parameter $\left(R_{n}\right)$ which correspondingly affects the depth of the device's notch. That is, when the ideal (lossless) tuning parameter estimates are compensated for by considering the dielectric losses, the tuning parameter errors are observed to consistently decrease. In general, the notch frequency parameter $\left(f_{n}\right)$ error decreases on the order of $1-2 \%$, while the errors associated with the notch resistance parameter $\left(R_{n}\right)$ are nearly halved. Additionally, the $\alpha$ parameter $\left(=R / R_{n}\right)$ error also decreases when the dielectric loss compensation scheme is implemented. Consequently, the consistent improvement in reconciling the tuning parameter errors suggests that dielectric compensation is a 
valuable tool for predicting and improving the performance of uniformly distributed $R C$ notch networks.

\section{REFERENCES}

[1] V. Uzunoglu, "Six possible routes to noninductive tuned circuitry," Electron., vol. 38, pp. 114-119, Nov. 1965.

[2] S. K. Mitra, ed., Active Inductorless Filters. New York: IEEE Press 1971 .

[3] R. Nandi, "Realization of all pass or notch filters: A simulated inductor approach," in IEE-IERE Proc. India, vol. 15, Nov.-Dec. 1977, pp. 254-258.

[4] C. K. Hager, "Distributed-parameter networks for circuit miniaturization," in Proc. AIEE-EIA-WCEMA Joint Electronics Components Conf., May 1959, pp. 195-203.

[5] C. K. Hager, "Network design of microcircuits," Electron., vol. 32, pp. $183-195,1963$.

[6] A. Smith, "Rejection filters with distributed R and C," in Proc. Electronics Components Conf., May 1960, pp. 23-28.

[7] W. M. Kaufman, "Theory of a monolithic null device and some novel circuits," in Proc. IRE, vol. 48, Sept. 1960, pp. 1540-1549.

[8] W. W. Happ and G. C. Riddle, "Limitations of film-type circuits consisting of resistive and capacitive layers," in IRE Int. Conv. Record, Mar. 1961, pp. 141-165.

[9] W. W. Happ and W. D. Fuller, "Design procedures for film type distributed parameter circuits," in Proc. Nat. Electronics Conf., Oct. 1961, pp. 597-610.

[10] W. M. Kaufman and S. J. Garret, "Tapered distributed filters," IRE Trans. Circuit Theory, vol. CT-9, pp. 329-336, Dec. 1962"

[11] R. W. Wyndrum, Jr., "Distributed RC notch networks," Proc IEEE, vol. 51, pp. 374-375, Feb. 1963.

[12] J. S. Bell, "A graphical method of designing notch filters," J. Inst. Engr. Australia, vol. 35, pp. 41-42, Mar. 1963.

[13] W. E. Newell, "A new class of single-element tunable RC nul circuits," J. Electron. Contr., vol. 15, pp. 183-195, 1963.

[14] G. Herskowitz and R. Wyndrum, Jr., "Design of distributed RC feedback networks for bandpass amplifiers," Semiconduct. Prod. Solid-State Tech., vol. 7, pp. 13-19, Jan. 1964."

[15] S. C. Dutta Roy, "On some three terminal lumped and distributed RC null networks," IEEE Trans. Circuit Theory, vol. CT-11, pp 98-103, Mar. 1964

[16] K. L. Su, "Analysis of a trigonometric $R C$ line and some applications," IEEE Trans. Circuit Theory, vol. CT-11, pp. 158-160, Mar. 1964.

[17] M. J. Gay, "The design of feedback tuned amplifiers using distributed bridged-T networks," Microelectron. Reliab., vol. 3, pp. 93-107, 1964.

[18] M. F. Ponomarev, V. P. Popov, and L. N. Kolesov, "The effect of complex loads on the frequency characteristics of selective RC circuits with distributed parameters," Soviet Radio Engr., vol. 8, pp. 260-262, May-June 1965

[19] _- "The effect of the base resistance in a distributed parameter RC circuit on the properties of a selective filter," Soviet Radio Engr. vol. 8, pp. 324-327, July-Aug. 1965.

[20] K. L. Su, "Selectivity of notch filters using nonuniform RC lines," Electron. Lett., vol. 1, no. 7, pp. 204-205, Sept. 1965.

[21] K. L. Su, "Effect of load conductance on the selectivity of notch filters," Electron. Lett., vol. 1, no. 8, pp. 217-219, Oct. 1965.

[22] M. J. Gay, "Selectivity of notch filters using nonuniform RC lines," Electron. Lett., vol. 1, no. 10, p. 293, Dec. 1965.

[23] O. Benes and J. Zima, "The design of silicon frequency selective RC networks," Microelectron. Reliab., vol. 4, no. 3, pp. 267-273, 1965.

[24] K. L. Su, "Selectivity of notch filters using nonuniform RC lines," Electron. Lett., vol. 2, no. 1, pp. 11-12, Jan. 1966

[25] S. Kleinheins, "Steepness of an exponentially tapered distributed RC notch filter," Electron. Lett., vol. 2, no. 7, pp. 263-264, July 1966.

[26] W. Kretz, "Steepness of an exponentially tapered distributed RC notch filter," Electron. Lett., vol. 2, no. 7, pp. 262-263, July 1966.

[27] S. C. Dutta Roy and B. A. Shenoi, "Notch networks using distributed RC elements," Proc. IEEE, vol. 54, pp. 1220-1221, Sept. 1966.

[28] K. L. Su, " $R C$ filters with staggered notch frequencies," Proc. IEEE, vol. 54 , no. 9, pp. 1199-1200, Sept. 1966

[29] S. Kleinheins, "Steepness of a loaded exponentially tapered distributed RC notch filter," Electron. Lett., vol. 2, no. 10, pp. 374-375, Oct. 1966
[30] V. M. Volkov and V. P. Popov, "Analysis of selective amplifiers constructed using RC microstructures with distributed parameters," Telecomm. Radio Engr., vol. 21, no. 1, pp. 86-89, Jan. 1967.

[31] M. F. Ponomarev and V. P. Popov, "Selective semiconductor (integrated) RC-circuit," Telecomm. Radio Engr., vol. 21, no. 4, pp. 104-109, Apr. 1967

[32] M. S. Ghausi and J. J. Kelly, Introduction to Distributed Parameter Networks. New York: Holt, Rinehart, and Winston, 1968.

[33] M. S. P. Lucas and D. G. Barker, "The effects of dielectric losses on the characteristics of a distributed RC notch network," Microelectron. Reliab., vol. 7, no. 1, pp. 105-106, 1968.

[34] V. I. Klyukin and A. M. Vorobyev, "Notch filter based on a cascaded RC network with distributed parameters," Radio Engr. Electron. Phys., vol. 132, no. 1, pp. 114-117, 1968.

[35] J. J. Golembeski, "Distributed RC network tuning," in Proc. Electronics Components Conf., May 1969, pp. 111-114.

[36] L. P. Huelsman, "The distributed lumped active network: its applications to filtering problems," IEEE Spectrum., vol. 6, pp. 51-58, Aug. 1969.

[37] L. P. Huelsman, "The values of the parameters of a distributed $R C$ null network," IEEE Trans. Circuit Theory, vol. CT-16, p. 376 Aug. 1969

[38] J. J. Golembeski, "Distributed RC notch network tuning," IEEE $J$ Solid-State Circuits, vol. SC-4, pp. 425-427, Dec. 1969.

[39] Y. Hattori, T. Hara, and D. Tanaka "Studies on Bessel RC lines," Inst. Atomic Energy Tech. Rep. Kyoto Univ., vol. 148, pp. 1-28, Jan. 1970

[40] V. V. Rudnev, L. I. Goryanina, and N. G. Nifontov, "Effect of leakage conductance and series distributed resistance on the characteristics of RC filters with distributed parameters," Radio Engr. and Electron. Phys., vol. 15, pp. 1316-1319, July 1970

[41] J. Stein, "A new look at distributed RC notch filters," Proc. IEEE, vol. 58, pp. 596-598, Apr. 1970

[42] L. Gruner, "Survey of the applications of nonuniform distributed parameter structures," Proc. IREE (Australia), vol. 39, pp. 22-25, Jan. 1971.

[43] S. B. Park, "An improved distributed RC notch filter and its application to an extremely insensitive bandpass amplifier," Proc. IEEE, vol. 59, pp. 314-315, Feb. 1971

[44] J. A. Carson, C. K. Campbell, P. Swart, and F. J. Vallo, "Effects of dielectric losses on the performance of evaporated thin film distributed RC notch filters," IEEE J. Solid-State Circuits, vol. SC-6, pp. $120-124$, June 1971

[45] P. Bowron, "Selectivity of null networks," Proc. IEEE, vol. 59, pp. 1117-1119, July 1971

[46] C. K. Campbell, "Transmission line graphical analysis of a distributed $R C$ notch filter," Proc. IEEE, vol. 59, pp. 1362-1363, Sept. 1971.

[47] S. C. Dutta Roy and R. P. Sah, "Dual input distributed RC notch filter," Indian J. Pure Appl. Phys., vol. 9, no. 9, pp. 762-763, Sept. 1971.

[48] P. L. Swart and C. K. Campbell, "Effect of inductance on the characteristics of a distributed $R C$ notch filter," Proc. IEEE, vol. 59, pp. 1371-1373, Sept. 1971.

[49] J. Watkins, "A laboratory version of the notch filter using a section of distributed resistance-capacitance transmission line," Int. J. Elec. Engr. Educ., vol. 9, pp. 373-380, Oct. 1971.

[50] V. D. Dmitriev and A. I. Merkulov, "Adjustment of RC rejection filters with distributed parameters," Izv. VUZ Radio Elektron., vol. 14 , pp. $1213-1218,1971$.

[51] G. B. Kozlov and G. S. Ostapenko, "Analysis of null RC filters," Izv. VUZ Radio Elektron., vol. 14, pp. 802-808, 1971.

[52] P. Bowron and G. Wilson, "The stability of irrational null networks," Proc. IEEE, vol. 60, pp. 327-328, Mar. 1972

[53] S. M. Bozic, C. A. Miller, and R. I. Salawu, "Lumped approximations to distributed RC notch networks for linear integrated circuits," Microelectron. Reliab., vol. 11, pp. 191-199, Apr. 1972.

[54] P. L. Swart and C. K. Campbell, "A voltage controlled tunable distributed $R C$ filter," IEEE J. Solid-State Circuits, vol. SC-7, pp. 306-308, Aug. 1972

[55] H. F. Benz and R. J. Mattauch, "A linear voltage tunable distributed null device," IEEE J. Solid-State Circuits, vol. SC-7, no. 6, pp. 499-503, Dec. 1972

[56] Y. Toba and $\mathbf{K}$. Mano, "On the characteristics and the optimum conditions for the operation of null networks composed of semiconductor distributed networks," Rec. Electron. Comm. Engr. Tohokyu Univ. Japan, vol. 42, pp. 18-22, Feb. 1973. 
[57] R. Singh and S. Venkateswaran, "Understanding notch filters," Electro. Tech. (India), vol. 17, pp. 57-62, Mar.-Apr. 1973

[58] Y. Toba and $\mathbf{K}$. Mano, "The realization of the effect for nonuniform distribution in semiconductor null networks," IEEE J. Solid-State Circuits, vol. SC-8, pp. 182-184, Apr. 1973.

[59] A. B. Bhattacharyya and M. L. Gupta, "An $R C$ notch filter with distributed shunt resistance," Proc. IEEE, vol. 61, pp. 1158-1159, Aug. 1973.

[60] A. V. Shkulipa, "Null networks with distributed RCG circuits," Radio Engr. Electron. Phys., vol. 18, pp. 1360-1364, Sept. 1973.

[61] L. P. Huelsman, "A three layer distributed RC network with two transmission zeros," in Proc. Seventh Asilomar Conf. on Circuits, Systems and Computers, Nov. 1973, pp. 393-395.

[62] P. Bowron and G. Wilson, "A selectivity comparison of the exponentially distributed and twin-T RC null networks," $A E U$, vol. 27, no. 12, pp. 505-507, Dec. 1973

[63] P. L. Swart and C. K. Campbell, "Effects of losses and parasitics on a voltage controlled tunable distributed $R C$ notch filter," IEEE $J$. Solid-State Circuits, vol. SC-9, no. 1, pp. 35-36, Feb. 1974

[64] J. Watkins, "Distributed $R C$ notch filters based on a circular geometry," IEEE Trans. Circuits Syst., vol. CAS-21, no. 2, pp. 271-274, Mar. 1974.

[65] L. P. Huelsman and S. Raghunath, "The values of the parameters of some multilayer distributed $R C$ null networks," IEEE Trans. Circuit Syst., vol. CAS-21, pp. 804-805, Nov. 1974.

[66] E. J. Stolinski and Z. H. Meiksin, "Thin-film distributed $R C$ parameter strain gauges," IEEE Trans. Electron Devices, vol. ED-22, pp. 102-108, Mar. 1975.

[67] A. El Sami Mostafa and G. P. Fiani, "Distributed RC structures as filters," in Proc. 1975 IEEE Int. Symp. on Circuits and Systems, Apr. 1975, pp. 155-157.

[68] B. S. Berenshtein and A. M. Vorobev, "Temperature stability and parameter sensitivity of nulling distributed RC filters," Izv. VUZ Radio Elektron., vol. 18, no. 5, pp. 78-79, May 1975.

[69] S. M. Bozic, C. A. Miller, and R. I. Salawu, "Effect of substrate resistance on a MOS distributed RC notch network," Microelectron. Reliab., vol. 14, no. 5-6, pp. 435-437, 1975.

[70] S. C. Dutta Roy and U. Kumar, "A rational two-port model of the uniformly distributed $R C$ structure," IEEE Trans. Circuits Syst., vol. CAS-23, pp. 56-58, Jan. 1976

[71] P. V. Ananda Mohan and V. Jaya Kumar, "Distributed $R C$ null network tuning," Proc. IEEE, vol. 64, pp. 362-363, Mar. 1976.

[72] P. H. K. Wong and L. Young, "A new voltage tunable distributed $R C$ notch filter suitable for SOS realization," Proc. IEEE, vol. 62 , pp. 523-524, Apr. 1977.

[73] M. J. R. Khan, "Notch filter characteristics of distributed parameter C-R-NC structures," J. Instr. Electron. Telecomm. Engr., vol. 23, pp. 275-280, May 1977.

[74] K. U. Ahmed and J. P. Agarwal, "An experimental study of shifting the null frequency of a thin film distributed parameter Ro-Co-KRo structure," J. IETE, vol. 23, pp. 413-414, July 1977 .
[75] M. L. Gupta, " Single-section lumped model for distributed $R C$ notch filters," Proc. IEEE, vol. 65, pp. 1723-1725, Dec. 1977.

[76] K. Pal, "An experimental study of the effect of an external resistor on the null frequency of an Ro-Co-KRo structure," J. IETE, vol. 24, p. 374 , Sept. 1978

[77] A. J. Walton, P. L. Moran and N. G. Burrow, "The application of finite element techniques to the analysis of distributed $R C$ networks," IEEE Trans. Comp., Hybrids, Manuf. Technol., vol. CHMT-1, pp. 309-315, Sept. 1978

[78] A. M. Ler and E. P. Sogolovskii, "Passive null filters in distributed parameter RC structures," Peradacha Inf., vol. 54, pp. 75-81, Oct. 1978.

[79] K. E. G. Pitt, "Thick film distributed notch filters," Microelectron., vol. 9 , no. 1 , pp. $18-21,1978$.

[80] S. I. Leppavaori and J. H. A. Rapeli, "Thick film distributed RC-networks for practical use," in Proc. Electronics Components Conf., May 1979, pp. 402-406.

[81] P. Bowron and C. Tapinos, "A transmission-line analog simulating thin-film distributed $R C$ elements," IEEE Trans. Comp. Hybrids, Manuf. Technol., vol. CHMT-2, pp. 330-336, Sept. 1979.

[82] U. Kumar, "Distributed RC notch network filters based on an elliptical geometry," Archiv fur Elektronik und Ubertragungstechnik, vol. 34, no. 12, pp. 517-518, Dec. 1980.

[83] S. Ahmad and R. Singh, "A composite dielectric thin-film notch filter," Thin Solid Films, vol. 67, pp. L63-L65, 1980.

[84] S. Ahmad and R. Singh, "High-quality dielectric film for distributed RC filters and amorphous semiconductors," Thin Solid Films, vol. 74 , pp. $165-171,1980$

[85] T. N. Yakimov and V. L. Velchev, "Thin-layer RC-structures with distributed parameters," Elektropromishlenost I Priborostroene, vol. 15 , no. 12 , pp. $462-463,1980$.

[86] S. Ahmad and R. Singh, "A simple method of analyzing distributed RC notch filters," Microelectron. J., vol. 12, no. 1, pp. 18-22, Jan. 1981.

[87] E. S. Kolesar, Jr. and R. M. Walser, "Novel realization of the uniformly distributed RC (URC) notch network," IEEE Trans. Educ., vol. E-28, pp. 173-176, Aug. 1985.

[88] E. S. Kolesar, Jr., "Dielectric loss effects on the performance of a thin-film, uniformly distributed RC notch network," in Proc. IEEE 1987 Nat. Aerospace and Electronics Conf. (NAECON), May 1987, pp. 20-24.

[89] E. S. Kolesar, Jr. and R. M. Walser, "Organophosphorus compound detection with a supported copper + cuprous oxide island film. part II. alternating current studies and sensor performance," Anal. Chem., vol. 60, no. 17, pp. 1731-1737, Sept. 1988.

[90] "Accuglass siloxane spin-on glass (SOG) material $\left(\mathrm{SiO}_{2}\right)$," Information Bulletin Application Notes, Allied Signal, Inc., Planarization and Diffusion Products Division, Aug. 1989.

[91] L. F. Shampine and R. C. Allen, Numerical Computing: An Introduction. Philadelphia, PA: W. B. Sanders, 1973. 